\title{
A Planting Template for Plug Flats
}

\author{
Charles W. Marr ${ }^{1}$
}

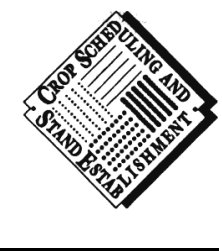

Additional index words. transplants, seeding, seeder

Summary. Seedlings are established in small growing containers to reduce cost of greenhouse space, while improving crop uniformity. These seedlings often are referred to as plugs. Vacuum seeders are used by larger growers to seed many flats per season (Bakos, 1983); however, individual growers, producing plants for their own use, may not be able to justify expensive seeding equipment. Several moderately priced vacuum seeders are available (Bartok, 1988). They consist of a metal tray with small drilled holes to hold the seed in place when a vacuum is applied to the tray from an external source. However, several problems with them exist. Seeds must be free of extraneous materials that might clog the small holes. A slight jarring of the plate, especially when the plate is turned upside down over the seed flat, may cause seeds to dislodge, resulting in unplanted cells in each flat. Also, different sizes of seeds and flats require completely different seeding plates and plate holders. A small grower may choose to seed flats by hand by placing seeds individually in each cell. This is feasible only for large-sized seeds or with pelleted seed. A simple, inexpensive, non-vacuum alternative design is presented and evaluated.

A $\mathrm{n}$ inexpensive, acrylic-plastic seeding template was developed and compared to vacuum (Speedy Seeder, 1 Lodi, Wis.) and hand seeding. The template consists of two sheets of 3-mm acrylic plastic cut to rectangular dimensions of the seed flat. The upper sheet has a $6-\mathrm{cm}$-tall "wall" glued to the outside with a small opening in the wall at one end, so excess seeds can be poured out. The bottom sheet is held in place by four glued tabs on each side, so that the bottom sheet could slide laterally. The bottom sheet is left slightly longer with a slot cut as a handle (Fig. 1). Because the template was tested using cabbage (Brassica oleraceae L. Capitata group cv. Conquest), 3-mm holes were drilled through both sheets. With the two sheets offset so that the holes are not in alignment, the template is operated by filling the top with seed, rotating the template so seed fills each hole, and pouring off excess seed. After placing the template over the seed flat, the bottom sheet is slipped to allow seed to fall through to the seed flat cavities.

The system was evaluated by comparing seeding times, thinning times, and cells with plants using unpelleted cabbage seed. Flats were prefilled and times were recorded for picking up the seed flats; pouring out or handling the required seed necessary; and seeding, covering, and placing the flat on a bench. Thinning times were recorded to include retrieving the flat, clipping excess plants with surgical scissors, and replacing the flat on the bench. Counts of full cells were

${ }^{\prime}$ Proffessor. Department of Horticulture, Kansas State University, Manhattan, KS 66506

Contribution no. 90-315-J of the Kansas Agr. Expt.. Sta. 


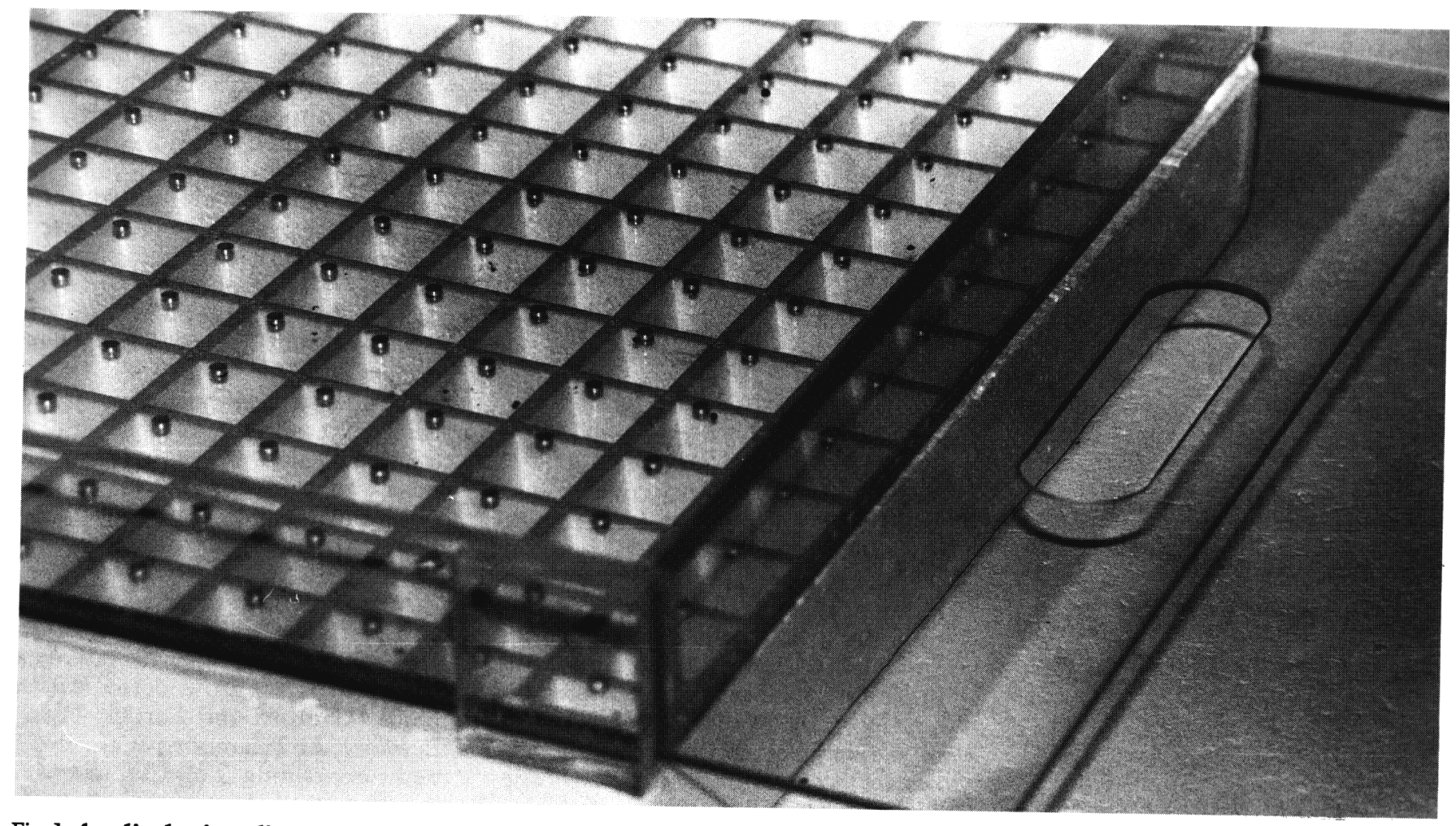

Fig. 1.Acrylic plastic seeding template placed over a 080A Todd planter flat (unfilled).

made about 10 days after thinning. Treatments consisted of single vacuum-seeding, vacuum-seeding twice over the same flat, hand-seeding to seed the flat as quickly as possible, a moderate seeding rate to attempt to place one seed in each cell, a slow seeding rate to singly place seed in each cell, and planting using the template. Two sets of four flats for each treatment were seeded ( $\mathrm{n}=8$ flats).

Vacuum seeding was moderately fast, although some time is needed for inverting the seeder to ensure that seeds do not dislodge. Rapid hand seeding had a shorter seeding time, because seeds only have to be poured out into the hand. However, significant time in thinning is required to remove excess plants that are usually very close together in the seed cell. The planting template compares favorably in thinning time to a moderate hand planting rate, but is faster (and less tedious) for seeding. Template-seeded cells frequently contained two seeds. A larger-seeded variety or slightly smaller seed holes

Table 1. Times to plant and thin cabbage seeds using band seeding, a vacuum seeder, and a planting template (mean of eight flats).

\begin{tabular}{llrrrr}
\hline & \multicolumn{3}{c}{ Time [min $\pm($ SD)] } & Cells with \\
\cline { 2 - 5 } Treatment & Seeding & \multicolumn{1}{c}{ Thinning } & \multicolumn{1}{c}{ Total } & plants (\%) \\
\hline Vacuum, once & $3.1(0.2)$ & $1.0(0.4)$ & $4.1(0.4)$ & $58(5.4)$ \\
Vacuum, twice & $4.3(0.3)$ & $3.8(0.8)$ & $8.2(0.7)$ & $91(2.7)$ \\
Hand, quickly & $1.7(0.2)$ & $13.8(2.1)$ & $15.5(2.2)$ & $95(1.9)$ \\
Hand, moderate & $3.7(0.2)$ & $2.8(0.7)$ & $6.5(0.8)$ & $96(1.8)$ \\
Hand, slowly & $5.2(0.4)$ & $0.7(0.2)$ & $5.9(0.4)$ & $97(0.6)$ \\
Template & $3.0(0.2$ & $2.3(0.3)$ & $5.3(0.5$ & $96(1.5)$ \\
\hline
\end{tabular}

Plant stands were estimated 10 days after thinning, with weak, defective plants or missing cells counted as empty. would vary the numbers of multiple seeds in each hole. Pelleted seed should be able to be planted with much greater assurance of one seed per cell. Another problem encountered with the template was static electricity that was generated when excess seed were poured off the template. This was reduced by treating the template with an application ofantistatic aerosol spray. No obvious problems in germination or phytotoxic effects on the cabbage seedlings were caused by this treatment.

Although reference to a commercially available template of this type was cited by Bartok (1988), no sources have been found. Material costs for the template were $\$ 18$, which compares favorably with the $\$ 300$ to $\$ 600$ initial cost of a vacuum seeder with an additional charge for more planting plates. Several templates could be used for various crop species or varieties. Limitations of the template are that it is not suited for anything other than nearly round or pelleted seed, so many small-seeded flower species would not be adaptable to this planting method. However, it may provide a seeding alternative for the small vegetable producer interested in alternatives for growing transplants in plug trays.

Seeding and thinning tunes reported in this study should be considered as relative to each other rather than as absolute values. Times represent total time of retrieving, preparing, and replacing flats, while, in actual commercial situations, an assembly line or group handling of flats most likely would be used.

\section{Literature Cited}

Bakos. 1983. Plugging into seeders. Flor. Rev. 172:22-24,26,29.

Bartok, J. 1988. Seeders. Conn Greenhouse Nwsl. 147:3-6. 